Provided for non-commercial research and education use. Not for reproduction, distribution or commercial use.

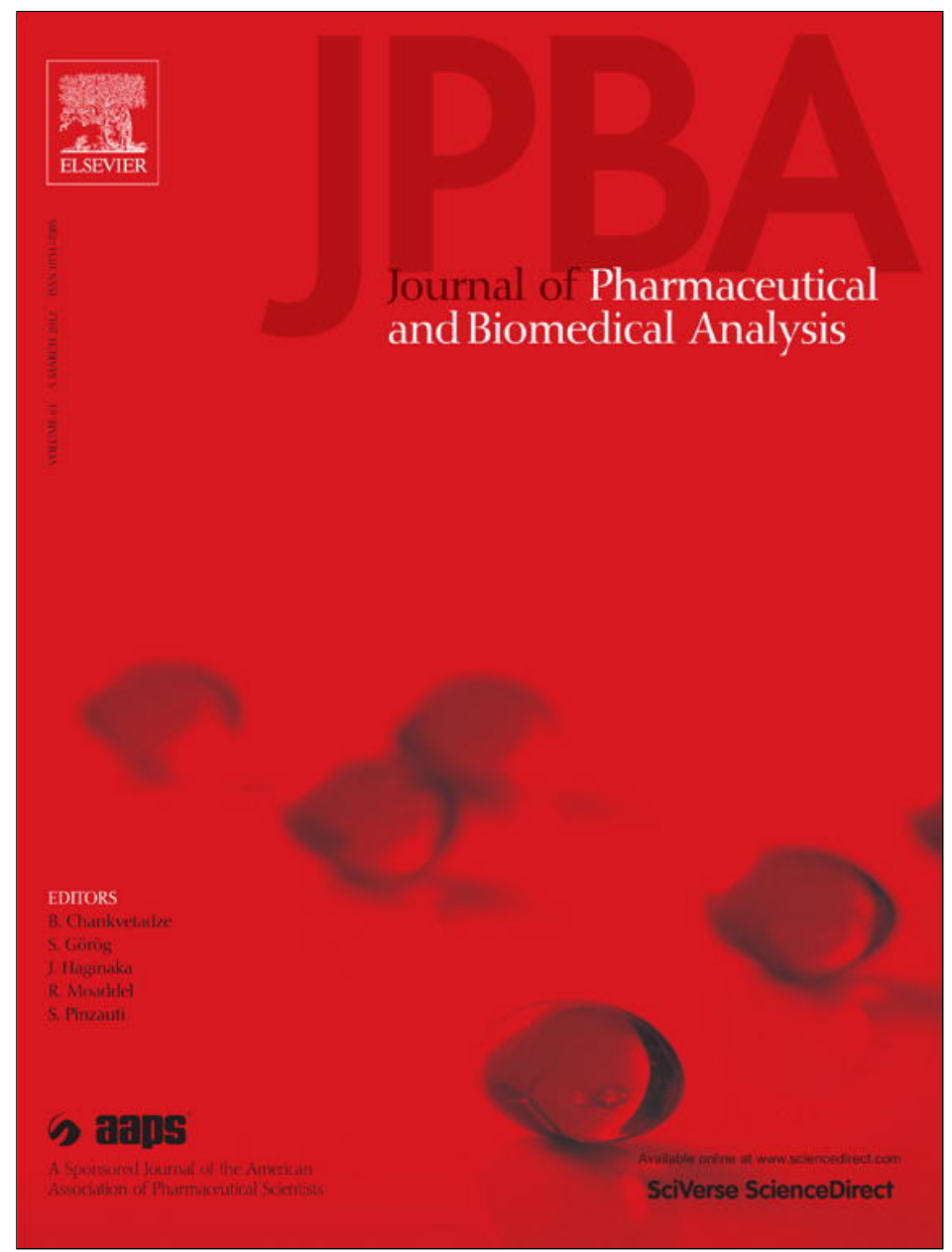

This article appeared in a journal published by Elsevier. The attached copy is furnished to the author for internal non-commercial research and education use, including for instruction at the authors institution and sharing with colleagues.

Other uses, including reproduction and distribution, or selling or licensing copies, or posting to personal, institutional or third party websites are prohibited.

In most cases authors are permitted to post their version of the article (e.g. in Word or Tex form) to their personal website or institutional repository. Authors requiring further information regarding Elsevier's archiving and manuscript policies are encouraged to visit:

http://www.elsevier.com/copyright 


\title{
Development of an UPLC-MS/MS method for the determination of antibiotic ertapenem on dried blood spots
}

\author{
Giancarlo la Marca ${ }^{a, b, *, 1}$, Elisa Giocaliere ${ }^{a, 1}$, Fabio Villanelli ${ }^{a, 1}$, Sabrina Malvagia a ${ }^{\text {, Silvia Funghini }}{ }^{\mathrm{a}}$, \\ Daniela Ombrone ${ }^{\mathrm{a}}$, Luca Filippi ${ }^{\mathrm{c}}$, Marina De Gaudio ${ }^{\mathrm{d}}$, Maurizio De Martino ${ }^{\mathrm{d}}$, Luisa Galli ${ }^{\mathrm{d}}$ \\ a Meyer Children's Hospital, Mass Spectrometry Lab, Florence, Italy \\ ${ }^{\mathrm{b}}$ Department of Pharmacology, University of Florence, Florence, Italy \\ ' Meyer Children's Hospital, Neonatal Intensive Care Unit, Florence, Italy \\ ${ }^{\mathrm{d}}$ Department of Sciences for Woman and Child's Health, University of Florence, Florence, Italy
}

\section{A R T I C L E I N F O}

\section{Article history:}

Received 7 October 2011

Received in revised form

14 December 2011

Accepted 14 December 2011

Available online 23 December 2011

\section{Keywords:}

Ertapenem

Carbapenem

DBS

UPLC-MS/MS

\begin{abstract}
A B S T R A C T
Ertapenem (Invanz ${ }^{\circledR}$ ) is a newly developed carbapenem $\beta$-lactam antimicrobial agent. The drug usage in pediatric age needs an accurate drug monitoring for effective patient management. The aim of this study was to evaluate the use of dried blood spot (DBS) specimens to measure ertapenem concentration during treatment. The analysis was performed by UPLC-MS/MS operating in multiple reaction monitoring (MRM) mode. The calibration curve in matrix was linear in the concentration range of $0.5-100 \mathrm{mg} / \mathrm{L}$ with correlation coefficient value higher than 0.997. Performance parameters of this method like lower limit of detection (LLOD, $0.2 \mathrm{mg} / \mathrm{L}$ ), lower limit of quantification (LLOQ, $0.5 \mathrm{mg} / \mathrm{L}$ ), matrix effect (20\%), intra- and inter-day imprecision (CV within than 15\%) and accuracy (between 94 and 155\%) of drug concentrations have been evaluated. The drug stability at different temperatures was tested for one month, to evaluate the risks of sample delivery at different climatic conditions.

The reported method allows now ertapenem analysis and offers many advantages for patients including the possibility of collecting samples at home.

This new assay is both precise and accurate and is especially suitable for therapeutic drug monitoring and pharmacokinetic studies in neonates in whom obtaining larger blood samples is not convenient or possible.
\end{abstract}

(C) 2011 Elsevier B.V. All rights reserved.

\section{Introduction}

Ertapenem is a carbapenem antibiotic with a broad spectrum activity and stability against a wide range of $\beta$-lactamases. It has limited activity against Pseudomonas aeruginosa, enterococci and methicillin-resistant Staphylococcus aureus and therefore its use is suggested in moderate-severe community-acquired infections, rather than in nosocomial infections. Since ertapenem has a good penetration into intra-abdominal organs and interstitial fluid, it has been suggested as a therapeutic option in patients with complicated bacterial infections [1]. Recently, internationally guidelines recommended ertapenem (as other carbapenems) as an alternative option for the treatment of complicated intra-abdominal infections (cIAIs) in adults and children aged $\geq 3$ months [2].

\footnotetext{
* Corresponding author at: Meyer Children's Hospital, Mass Spectrometry Lab, Florence, Italy. Tel.: +39 0555662988; fax: +39 0555662489.

E-mail address: g.lamarca@meyer.it (G. la Marca).

1 These authors equally contributed to this work.
}

The role of ertapenem in the treatment of complicated bacterial infections in children is, up to now, very limited. Since it has in vitro activity against the majority of the extended-spectrum betalactamase (ESBL)-producing Escherichia coli and Klebsiella species, its use in complicated urinary tract infections (cUTIs), other than in cIAIs, is under investigation [3]. At the present, some infectious disease specialists suggest that ertapenem could be a good therapeutic option in complicated community-acquired bacterial infections, reserving the use of antipseudomonal carbapenems for infections where Pseudomonas aeruginosa is frequently implicated, thus reducing the selective pressure on the selection of carbapenem-resistant Pseudomonas spp.

Ertapenem has a favorable pharmacokinetic (PK) profile that allows once-daily (OD) administration in adults after intravenous and intramuscular administration. Data on PK profile in children younger than 12 years showed that clearance of ertapenem is about 2 -fold higher as compared to adults [4]. Consequently, the recommended intravenous dosage is $1 \mathrm{~g}$ OD in patients aged $\geq 13$ years and $15 \mathrm{mg} / \mathrm{kg}$ twice-daily (to a maximum of $1 \mathrm{~g} /$ day) in children aged 3 months to 12 years [4]. 
To the best of our knowledge, no pediatric data on ertapenem PK profile in newborns and children younger than 3 months, nor PK data after intramuscular administration are available.

Several LC-UV methods have been reported in literature for the determination of carbapenem antibiotics both in biological samples such as plasma, serum, urine, bronchial secretions and in tissue samples. On the other hand, only few LC-MS methods have been published for the identification and quantization of carbapenem compounds or their degradation products [5-8]. As is well known, PK studies are difficult to perform in younger children, since they require collection of many blood samples in the same day with a considerable discomfort for the patients. Thus, an attracting and potential method to easily obtain samples for PK studies in children is collection of whole blood samples onto filter paper (dried blood spot or DBS). DBS specimens are commonly used for neonatal screening of metabolic diseases, cystic fibrosis and hypothyroidism in micro-blood samples. Some studies recently evaluated the use of DBS for therapeutic drug monitoring (TDM) and toxicology in adults $[9,10]$. Some studies, also from our group, applied the DBS technique to evaluate drug concentrations in newborns, infants and children [11-15]. These reports showed that the accuracy of TDM studies using DBS is comparable to that of traditional TDM studies on plasma which require larger blood volumes. The UPLC-MS/MS method, here described, represents a robust, highly specific and sensitive approach to quantify ertapenem on dried blood spots. Sensitivity enhancement, required in quantitative analysis, and also selectivity are obtained acquiring multiple transition pairs.

\section{Materials and methods}

\subsection{Standards}

Ertapenem was provided by Merck Sharp and Dohme (Rome, Italy). A stock solution of $1 \mathrm{~g} / \mathrm{L}$ was prepared in water and stored at $-80^{\circ} \mathrm{C}$ in different aliquots for no longer than six months. Successive dilutions were made using HPLC grade water. All chemicals and solvents were of the highest purity available from commercial sources and used without any further purification. Analytical grade methanol, acetonitrile and water were purchased from Panreac (Barcelona, Spain).

\subsection{Sample preparation}

Spiking studies were conducted using a pool of human blood from healthy donors; we evaluated linearity by analyzing fortified $3.2 \mathrm{~mm}$ dried blood spots prepared at 0.5, 1.5, 10, 50 and $100 \mathrm{mg} / \mathrm{L}$ on filter paper $\left(903^{\circledR}\right.$, Whatman GmbH, Dassel Germany). The amount of blood used to prepare spots was $20 \mu \mathrm{L}$ in order to produce homogeneous spots [16].

DBS samples were stored at $-20^{\circ} \mathrm{C}$ in a sealed plastic bag containing desiccant until analysis. One $3.2 \mathrm{~mm}$ diameter disk (containing about 3.3-3.4 $\mu \mathrm{L}$ of blood) was punched from each DBS sample and extracted with $200 \mu \mathrm{L}$ of a 30/70 of water/methanol (v/v) solution. Samples were put in an orbital shaker and kept at $37^{\circ} \mathrm{C}$ for $25 \mathrm{~min}$. The extracts were transferred into a new 96 -well plate and analyzed immediately.

\subsection{Validation procedures}

The method was validated in terms of linearity, precision, accuracy, extraction recovery, matrix effect and stability. Calibration curve was prepared by spotting on filter paper spiked human control blood to obtain concentrations of $0,0.5,1.5,5,10,20,50$ and $100 \mathrm{mg} / \mathrm{L}$. Intra-day precision data were evaluated by ten replicate analysis of five different ertapenem concentrations on the same day. Inter-day precision data were determined by the analysis of five different ertapenem concentrations on 10 different days.

To calculate the linear regression, the peak area was plotted against the drug concentration in milligrams per liter.

The stability study on DBS samples was evaluated up to one month after storage at $-20^{\circ} \mathrm{C},+4^{\circ} \mathrm{C}$, room temperature and $+37^{\circ} \mathrm{C}$.

\subsection{Mass spectrometry}

The samples and the calibration curve samples were analyzed on a Agilent (Waldbronn, Germany) 6430 bench-top Triple-Quad Mass Spectrometer equipped with an Electrospray source (ESI); the ESI source operated in positive ion mode, using the following setting: capillary voltage $5000 \mathrm{~V}$, fragmentor voltage $80 \mathrm{~V}$ for each transition, drying gas flow $9 \mathrm{~L} / \mathrm{min}$ of nitrogen, temperature $325^{\circ} \mathrm{C}$, nebulizer gas $35 \mathrm{psi}$. The following transitions were monitored in MRM mode: $m / z$ 476.2 > 432.2 (quantifier), $m / z 476.2>390.1$ (qualifier) and $m / z 476.2>233.1$ (qualifier). Optimal collision energies were found at 20,18 , and $18 \mathrm{~V}$, and the resulting cell acceleration voltage was $+7 \mathrm{~V}$ for all transitions.

The quantitation experiments were undertaken by using a Series 1290 Infinity LC System (Agilent Technologies, Waldbronn, Germany) UHPLC Capillary Pump coupled to an Agilent 6430, both being fully controlled from the Mass Hunter data system.

The analytical column was an Agilent Zorbax Eclipse Plus C18, Rapid Resolution $1.8 \mu \mathrm{m}, 2.1 \mathrm{~mm} \times 50 \mathrm{~mm}$ (Agilent Technologies, Waldbronn, Germany) operating at $0.4 \mathrm{~mL} / \mathrm{min}$ flow rate and using water (A) and acetonitrile (B) both containing $0.1 \%$ formic acid as mobile phase. The column was maintained at $60^{\circ} \mathrm{C}$ during the run. The chromatographic separation was obtained using a fast gradient starting from a $95 \%$ of solution A and $5 \%$ of solution B. The 95\% of organic solvent was reached in $1 \mathrm{~min}$ and maintained for $15 \mathrm{~s}$; initial conditions were restored in $5 \mathrm{~s}$ and the column equilibrated for $1 \mathrm{~min}$. The total running time was $2.2 \mathrm{~min}$ long and the ertapenem retention time was fixed to $1.04 \mathrm{~min}$. The eluent from the column was directed into the Electrospray source without split. Three microliters of the extracted sample were injected for the UPLC-MS/MS experiments.

System control, data acquisition and interpretation were made with the Agilent Mass Hunter software (Version B.04.00) software including the Qualitative package (for chromatographic and spectral interpretation) and the Quantitative Software (for quantitative information generation). Calibration curves were set up with the Mass Hunter Quantitative program using a linear least-square regression non-weighted.

\section{Results and discussion}

Dried blood spot sampling is increasingly becoming a good alternative to traditional plasma samples for biochemical analysis. The emerging technology offers great opportunities for improved patient care especially in the pediatric population where is generally difficult and unethical to obtain sufficient number of blood samples.

In this work, we have developed a method for the analysis of ertapenem concentrations in UPLC-MS/MS performed with only a few drops of blood and therefore very appealing for its application in pharmacokinetic studies involving infants and very young children. Fig. 1 shows the MS/MS spectrum obtained by fragmenting the precursor ion (476.2 Th) of ertapenem under the above described conditions. From these experiments, the resulting most selective ion-pair transition for the quantitative experiment (MRM) was $476.2>432.2$ while $476.2>390.1$ and $476.2>233.1$ were used as qualifier transitions. 


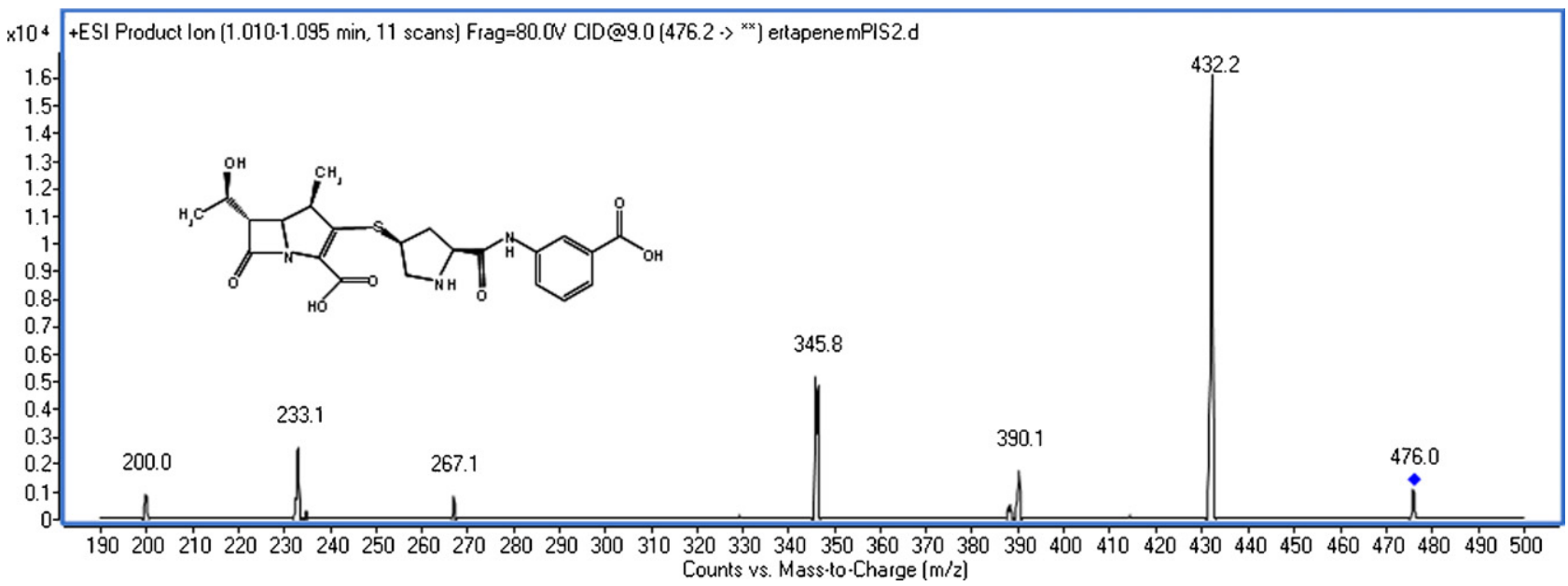

Fig. 1. Product ion scan and molecular structure of ertapenem.

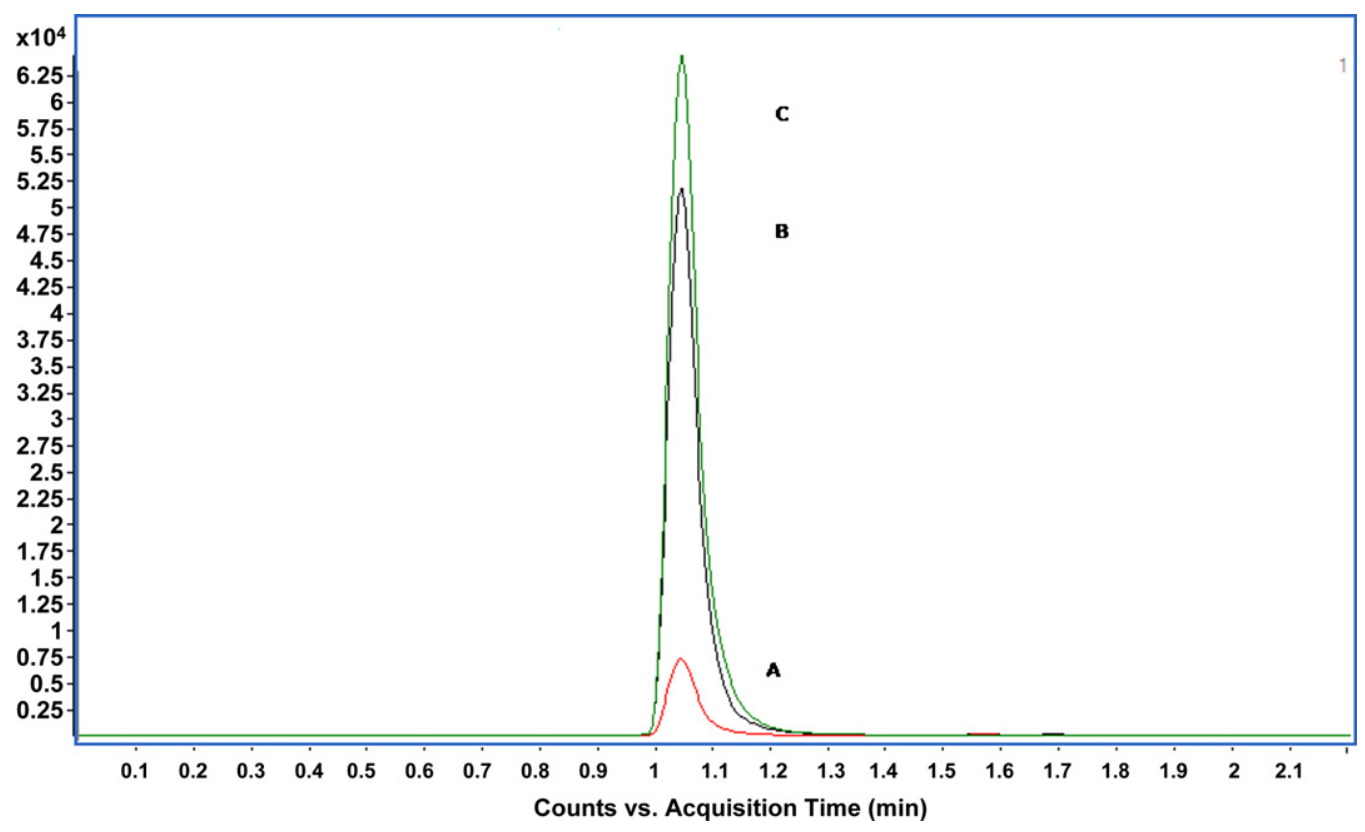

Fig. 2. Comparison among the chromatograms from a blank solvent sample spiked with ertapenem ( $5 \mathrm{mg} / \mathrm{L})$ (C) versus a ertapenem standard solution ( $5 \mathrm{mg} / \mathrm{L}) 70 / 30$ of methanol/water added to an extracted DBS blank sample (B) and an extracted DBS fortified with $5 \mathrm{mg} / \mathrm{L}$ of ertapenem (A).

Once the transitions were chosen, sample preparation was optimized adjusting many variables in the extraction process such as extraction solution composition, volume, time and temperature.

Different extraction solutions were examined and compared with the objective of choosing the best extraction mixture. The organic solvents used were methanol or acetonitrile with different percentages of water (from 50 to $10 \%$ ). The more efficient extraction solution, with the highest extraction yield, was found to be $30 / 70$ of water/methanol $(\mathrm{v} / \mathrm{v})$. The volume of extraction solution $(200 \mu \mathrm{L})$ was chosen in order to combine high extraction capacity with a minimal sample dilution. A successive extraction using the same conditions on the exhausted spot produced less than $10 \%$ compared to the first one.We studied the extraction time between 10 and 60 min but no subsequent increase in the peak area was reached after $25 \mathrm{~min}$ (data not shown). Additionally, extraction temperature was test at $25^{\circ} \mathrm{C}, 37^{\circ} \mathrm{C}$ and $60^{\circ} \mathrm{C}$. The best extraction yield occurred at $37^{\circ} \mathrm{C}$

Evaluation of drug extraction procedure from DBS, expressed as the ratio of the areas of the drug fortified DBS extract to that of blank DBS spiked after extraction was determined to be $15 \%$ (Fig. 2 , traces $\mathrm{A}$ and $\mathrm{B}$ ).
Table 1

Intra- and inter-day ertapenem reproducibility on DBS assessed by \% CV calculations.

\begin{tabular}{lcrrr}
\hline Intraday & & & & \\
\hline $\begin{array}{l}\text { Expected concentration } \\
(\mathrm{mg} / \mathrm{L})\end{array}$ & Mean $(n=10)$ & $\mathrm{SD}$ & $\% \mathrm{CV}$ & Accuracy \% \\
\hline 0.5 & 0.78 & 0.04 & 5.12 & 155 \\
1.5 & 1.70 & 0.12 & 7.05 & 113 \\
10 & 10.47 & 0.68 & 6.49 & 105 \\
50 & 47.44 & 2.04 & 4.30 & 95 \\
100 & 102.56 & 7.53 & 7.34 & 103 \\
& & & & \\
Interday & & & & \\
\hline Expected concentration & Mean $(n=10 \times 3)$ & $\mathrm{SD}$ & $\% \mathrm{CV}$ & Accuracy \% \\
$(\mathrm{mg} / \mathrm{L})$ & & & & \\
\hline 0.5 & 0.53 & 0.05 & 9.43 & 105 \\
1.5 & 1.49 & 0.22 & 14.77 & 99 \\
10 & 10.70 & 1.59 & 14.86 & 107 \\
50 & 46.90 & 1.60 & 3.41 & 94 \\
100 & 99.44 & 3.31 & 3.32 & 99 \\
\hline
\end{tabular}




\section{$5 \mathrm{mg} / \mathrm{L}$}

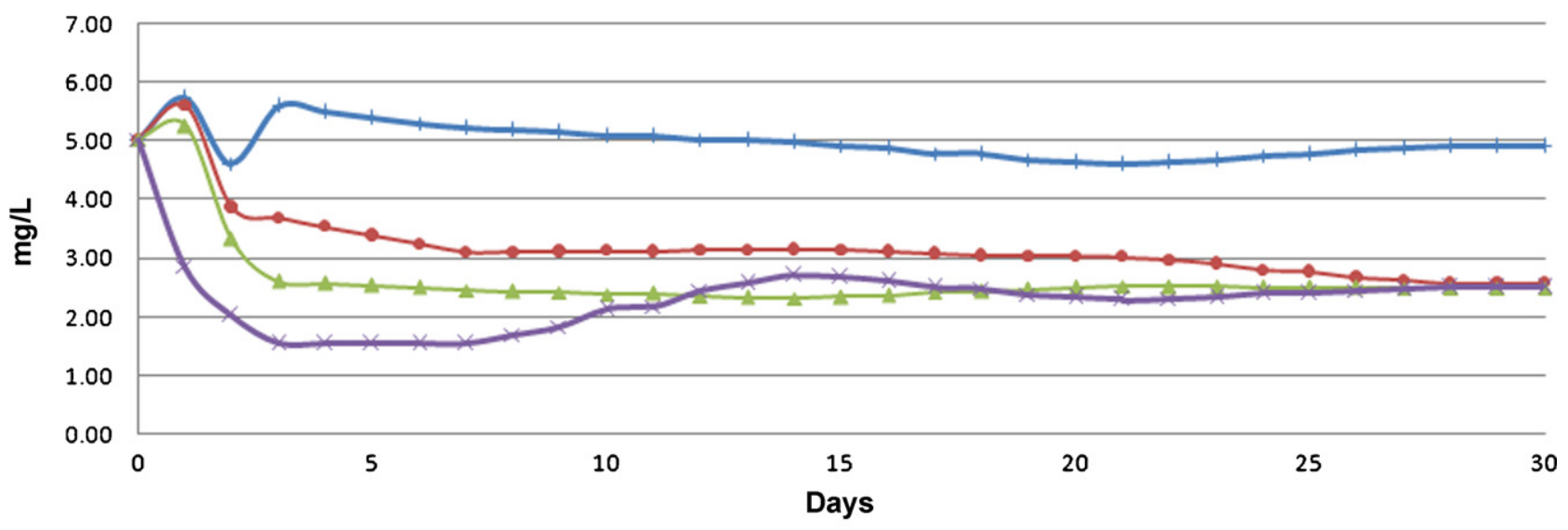

$\longrightarrow 5 \mathrm{mg} / \mathrm{L} \mathrm{T} .-20^{\circ} \mathrm{C} \longrightarrow 5 \mathrm{mg} / \mathrm{L} \mathrm{T} .4^{\circ} \mathrm{C} \longrightarrow 5 \mathrm{mg} / \mathrm{LR} . \mathrm{T} . \longrightarrow 5 \mathrm{mg} / \mathrm{L} \mathrm{T} .+37^{\circ} \mathrm{C}$

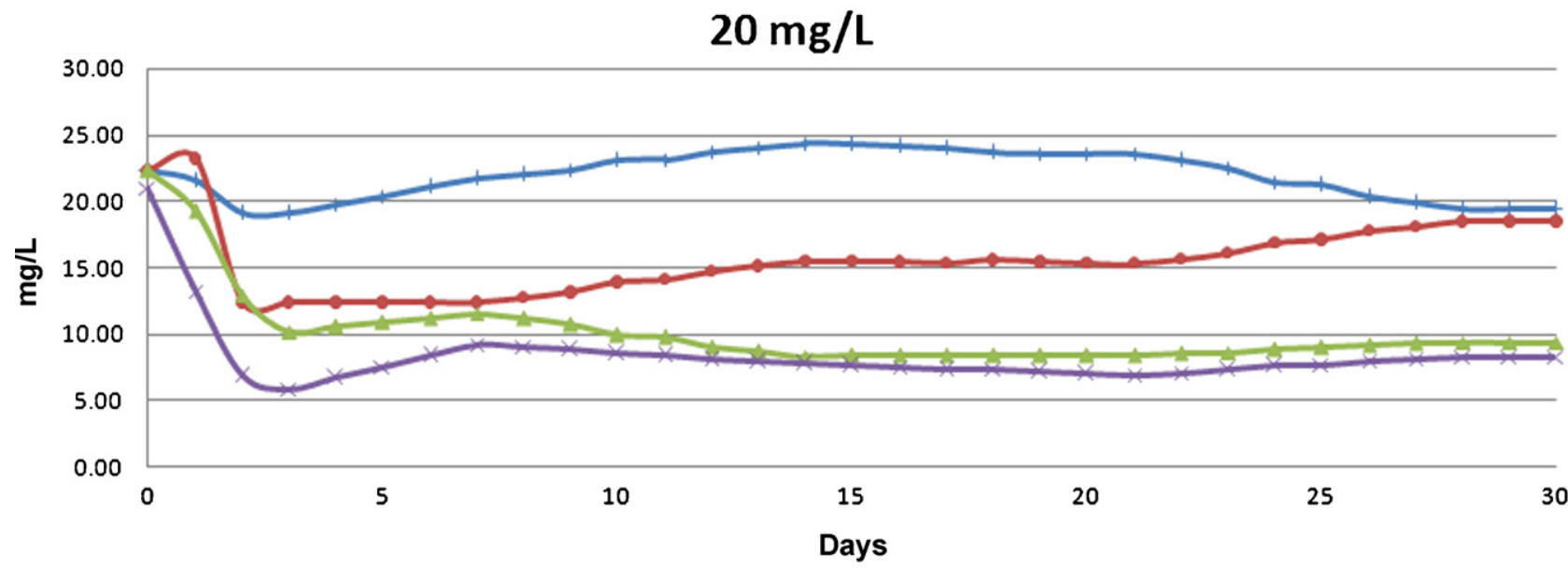

$\longrightarrow 20 \mathrm{mg} / \mathrm{L} \mathrm{T} .-20^{\circ} \mathrm{C} \longrightarrow 20 \mathrm{mg} / \mathrm{L} \mathrm{T} .+4^{\circ} \mathrm{C} \longrightarrow 20 \mathrm{mg} / \mathrm{L} \mathrm{R} . \mathrm{T} . \longrightarrow 20 \mathrm{mg} / \mathrm{L} \mathrm{T} .+37^{\circ} \mathrm{C}$

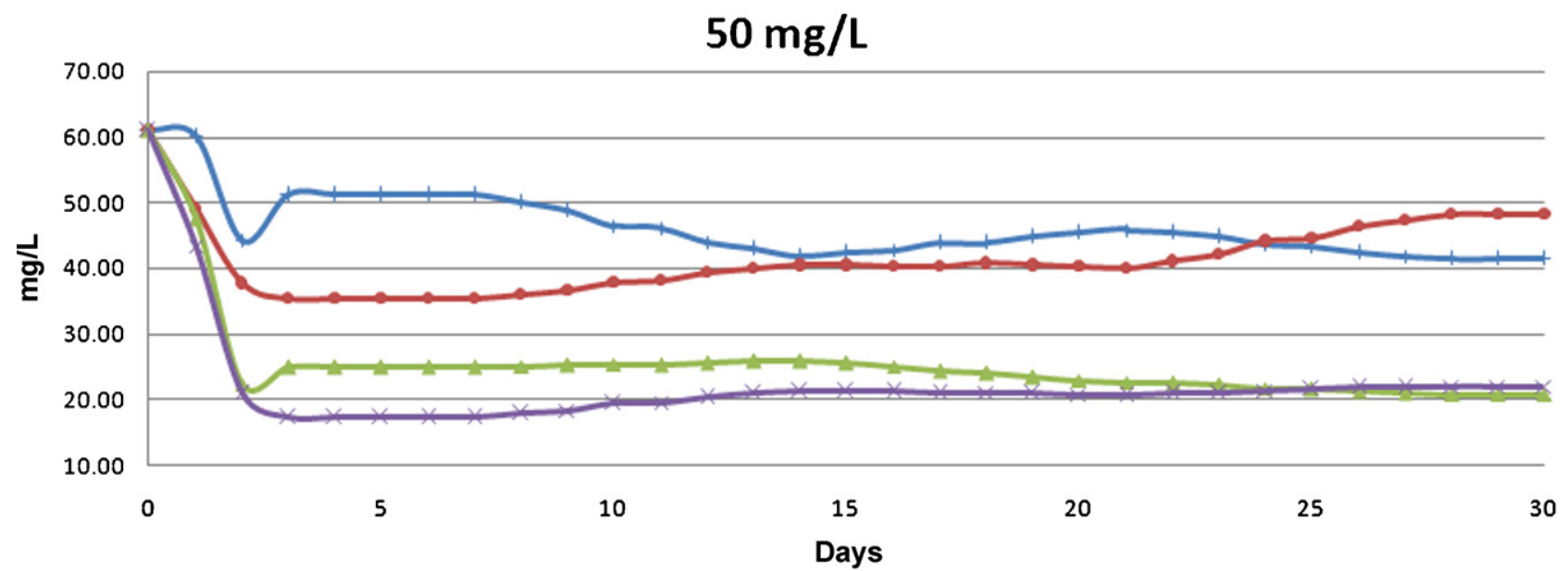

$\longrightarrow 50 \mathrm{mg} / \mathrm{L} \mathrm{T} .20^{\circ} \mathrm{C} \longrightarrow 50 \mathrm{mg} / \mathrm{L} \mathrm{T} .+4^{\circ} \mathrm{C} \longrightarrow 50 \mathrm{mg} / \mathrm{LR} . \mathrm{T} . \longrightarrow 50 \mathrm{mg} / \mathrm{L} \mathrm{T} .+37^{\circ} \mathrm{C}$

Fig. 3. Stability of ertapenem investigated at 4 different temperatures: $-20^{\circ} \mathrm{C},+4{ }^{\circ} \mathrm{C}$, room temperature and $+37^{\circ} \mathrm{C}$ for a month by repeat injection of 3 DBS spiked samples $(5,20$, and $50 \mathrm{mg} / \mathrm{L})$. 
The difference between (B) and (A) could be due to a significant portion of drug bounded to the blood proteins, as reported from Musson et al. [17]. This suggested us that the extraction solution is able to extract the total free ertapenem from DBS.

We tested also different times to equilibrate the sample after the ertapenem standard spiking (data not shown) to verify the influence of time in the protein binding on the free drug portion. The equilibration time range investigated was from 20 to $120 \mathrm{~min}$ at room temperature but any changes in the extracted concentration were observed. Therefore after 20 min of equilibration, each spiked blood sample was spotted on filter paper.

Matrix effect is shown by the ratio of extracted DBS sample spiked post-extraction and spiked solvent sample (Fig. 2, traces B and C); this value represents a loss of $20 \%$ of the analyte signal (ion suppression) due to alterations in ionization efficiency.

One of the most important features for screening method is a fast runtime analysis. It allows processing many samples in a short period of time. Moreover the resolution is another fundamental parameter and the column we used was a $1.8 \mu \mathrm{m}$ stationary phase column, coupled to a superior specificity of a triple quadrupole system operating in MS/MS mode. The injection volume was maintained low to avoid the system contamination from the matrix interferences and column over loading. In this new method the original sample is approximately 60 times diluted and the sample amount injected is $0.172 \mu \mathrm{L}$. In these conditions the sensitivity achieved is enough to afford the analyzed samples, obtaining robust performances, with the lowest sample preparation possible. Ertapenem was retained by the column enough to be separated from the salts, which represents the main ion suppression source for biological samples analysis. Inter-assay variability of calibration data obtained over concentrations of $0.5-100 \mathrm{mg} / \mathrm{L}$ was monitored on 4 consecutive weeks. The average slope, intercept, and coefficient of linear regression $\left(r^{2}\right)$ were $964,-427$ and 0.9987 ( $\mathrm{SD} \pm 0.001$, range $0.9970-0.9999$ ). A correlation coefficient $>0.9950$ is generally considered as the evidence of an acceptable fit of the data to the regression line.

In order to evaluate punching location impact and the homogeneity of drug distribution, experiments on several spots from the same drop of blood have been performed; no significant differences were detected. This fact is due to the low spotted volume on paper $(20 \mu \mathrm{L})$ as elsewhere reported [17].

In order to assess the robustness of the method, five spiked levels were used $(0.5,1.5,10,50$ and $100 \mathrm{mg} / \mathrm{L})$ and each was processed ten times in one day, resulting in an intra-day repeatability below $7 \%$ for all values (Table 1 ). The inter-day repeatability obtained in four separate assays for four weeks was better than $15 \%$ (Table 1 ). The limit of detection (LOD) and lower limit of quantification (LLOQ) of this method were determined from the coefficient of variation of a known concentration of reference standards. The LOD for this assay, calculated from 5 times the noise level of the response, in DBS was $0.2 \mathrm{mg} / \mathrm{L}$. The LLOQ for this assay calculated from 15 times the noise level of the response, is $0.5 \mathrm{mg} / \mathrm{L}$.

We investigated the effect of storage time and storage temperature at four different concentration levels $(0.5,5,20$ and $50 \mathrm{mg} / \mathrm{L})$ on spiked DBS samples. Ertapenem seems to be not stable under the tested temperatures $\left(+4{ }^{\circ} \mathrm{C}\right.$, room temperature and $\left.+37^{\circ} \mathrm{C}\right)$, with the exception of $-20^{\circ} \mathrm{C}$ (Fig. 3). In literature data related to the ertapenem stability reported a rapid degradation in solution and for long-term storage freeze at $-20^{\circ} \mathrm{C}$ is required $[7,16]$. Data related to the LLOQ $(0.5 \mathrm{mg} / \mathrm{L})$ stability are not shown in Fig. 3, because of the drug concentration after $24 \mathrm{~h}$ decreased under the limit of quantification. Usually the DBS sampling procedure helps the molecule stabilization, allowing collection, shipping and delivery at room temperature $[16,18]$. In this case the DBS sampling advantage remains, but the shipment must be performed at $-20^{\circ} \mathrm{C}$.

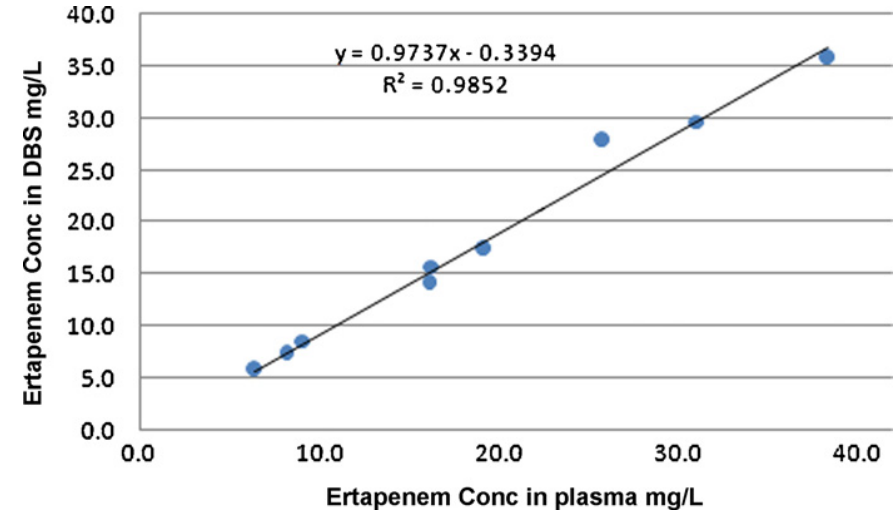

Fig. 4. Relationship between ertapenem levels in plasma and corresponding dried blood spots. Values represent the mean of duplicate experiments.

To verify the correlation between data obtained on dried blood spot and plasma, since no patients receiving ertapenem were available, three different blood samples at distinct hematocrit levels (low, medium and high) from healthy donors were selected.

For each blood sample three aliquots were prepared and spiked at 5,10 and $20 \mathrm{mg} / \mathrm{L}$ of ertapenem. Samples were equilibrated for $20 \mathrm{~min}$, then $20 \mu \mathrm{L}$ of blood were spotted on paper and the remaining blood was centrifuged to obtain plasma. The DBS samples were extracted as reported in Section 2; $200 \mu \mathrm{L}$ of extraction mixture were added to $2 \mu \mathrm{L}$ of plasma, vortexed and centrifuged to precipitate proteins. Three microliters of supernatant were injected. A good correlation $\left(R^{2}=0.9850\right)$ between ertapenem plasma and ertapenem levels measured in the corresponding DBS after real haematocrit correction was observed (Fig. 4). This confirms the validity of DBS analysis as an alternative to plasma drug.

The method will be helpful in processing large number of samples for patient's treatment monitoring at follow-up. Use of DBS for sampling requires little volume of blood spotted and dried on card, with great advantages over conventional plasma sampling being less invasive, particularly in pediatric population.

\section{Conclusions}

The use of DBS offers an easy way of collecting, storing, and shipping samples and is a non-invasive method because blood can be obtained from finger pricks sampling.

In order to keep stability for long term storage, ertapenem should be stored at low temperature $\left(-20^{\circ} \mathrm{C}\right)$.

A good correlation between drug levels measured in plasma and in the corresponding DBS after correction for real hematocrit was observed.

In this work, we developed a method for the "on DBS assay" of ertapenem by using UPLC-MS/MS. It could be considered very appealing for its application for TDM or in pharmacokinetic studies involving infants and very young children.

\section{References}

[1] M.E. Falagas, G. Peppas, G.C. Makris, D.E. Karageorgopoulos, D.K. Matthaiou, Meta-analysis: ertapenem for complicated intra-abdominal infections, Aliment. Pharmacol. Ther. 27 (2008) 919-931.

[2] J.S. Solomkin, J.E. Mazuski, J.S. Bradley, K.A. Rodvold, E.J. Goldstein, E.J. Baron, P.J. O'Neill, A.W. Chow, E.P. Dellinger, S.R. Eachempati, S. Gorbach, M. Hilfiker, A.K. May, A.B. Nathens, R.G. Sawyer, J.G. Bartlett, Diagnosis and management of complicated intra-abdominal infection in adults and children: guidelines by the Surgical Infection Society and the Infectious Diseases Society of America Clin. Infect Dis. 50 (2010) 133-164.

[3] N. Dalgic, M. Sancar, B. Bayraktar, E. Dincer, S. Pelit, Ertapenem for the treatment of urinary tract infections caused by extended-spectrum $\beta$ lactamase-producing bacteria in children, Scand. J. Infect Dis. 43 (2011) 339-343. 
[4] S.M. Abdel-Rahman, G.L. Kearns, S. Topelberg R.F. Jacobs, G.C. Mistry, A. Majumdar, Y. Xu, J.A. Wagner, C.J. Kitchen, M. Groff, G. Herman, J.L. Blumer, Pharmacokinetics and tolerability of single-dose intravenous ertapenem in infants, children, and adolescents, Pediatr. Infect Dis. J. 29 (2010) 1072-1076.

[5] Z. Zhao, X.Z. Qin, R.A. Reed, Identification by LC/MSn of degradated of a novel carbapenem antibiotic in an aqueous matrix, J. Pharm. Biomed. Anal. 29 (2002) 173-181.

[6] M.W.R. Pletz, M. Rau, J. Bulitta, A. De Roux, O. Burkhardt, G. Kruse, M. Kurowski, C.E. Nord, H. Lode, Ertapenem pharmacokinetics and impact on intestinal microflora, in comparison to those of ceftriaxone, after multiple dosing in male and female volunteers, Antimicrob. Agents Chemother. 48 (2004) 3765-3772.

[7] T. Koal, M. Deters, K. Resch, V. Kaever, Quantification of the carbapenem antibiotic ertapenem in human plasma by a validated liquid chromatography-mass spectrometry method, Clin. Chim. Acta 364 (2006) 239-245.

[8] S. Lefeuvre, N. Venisse, S. Marchand, M. Bachelet, W. Couet, A simple and sensitive liquid chromatography-tandem mass spectrometry assay for the quantification of ertapenem in microdialysate, J. Chromatogr. B: Analyt. Technol. Biomed. Life Sci. 862 (2008) 242-245.

[9] G. Emmons, M. Rowland, Pharmacokinetic considerations as to when to use dried blood spot sampling, Bioanalysis 2 (2010) 1791-1796.

[10] L. Filippi, C. Poggi, G. la Marca, S. Furlanetto, P. Fiorini, G. Cavallaro, A. Plantulli, G. Donzelli, R. Guerrini, Oral topiramate in neonates with hypoxicischemic encephalopathy treated with hypothermia: a safety study, J. Pediatr. 157 (2010) 361-366.
[11] N. Spooner, Dried blood spot sampling for quantitative bioanalysis: time for a revolution? Bioanalysis 2 (2010) 1781.

[12] N. Spooner, Y. Ramakrishnan, M. Barfield, O. Dewit, S. Miller, Use of DBS sample collection to determine circulating drug concentrations in clinical trials: practicalities and considerations, Bioanalysis 2 (2010) 1515-1522.

[13] G. la Marca, S. Malvagia, L. Filippi, P. Fiorini, M. Innocenti, F. Luceri, G. Pieraccini, G. Moneti, S. Francese, F.R. Dani, R. Guerrini, Rapid assay of topiramate in dried blood spots by a new liquid chromatography-tandem mass spectrometric method, J. Pharm. Biomed. Anal. 48 (2008) 1392-1396.

[14] G. la Marca, S. Malvagia, L. Filippi, M. Innocenti, A. Rosati, M. Falchi, S. Pellacani, G. Moneti, R. Guerrini, Rapid assay of rufinamide in dried blood spots by a new liquid chromatography-tandem mass spectrometric method, J. Pharm. Biomed. Anal. 54 (2011) 192-197.

[15] G la Marca, S. Malvagia, L. Filippi, F. Luceri, G Moneti, R. Guerrini, A new rapid micromethod for the assay of phenobarbital from dried blood spots by LC-tandem mass spectrometry, Epilepsia 50 (2009) 2658-2662.

[16] W. Li, F.L. Tse, Dried blood spot sampling in combination with LC-MS/MS for quantitative analysis of small molecules, Biomed. Chromatogr. 24 (2010) 49-65.

[17] D.G. Musson, K.L. Birk, C.J. Kitchen, J. Zhang, J.Y. Hsieh, W. Fang, A.K. Majumdar, J.D. Rogers, Assay methodology for the quantitation of unbound ertapenem, a new carbapenem antibiotic, in human plasma, J. Chromatogr. B: Analyt. Technol. Biomed. Life Sci. 783 (2003) 1-9.

[18] R. Garcia Boy, J. Henseler, R. Mattern, G. Skopp, Determination of morphine and 6 -acetylmorphine in blood with use of dried blood spots, Ther. Drug Monit. 30 (2008) 733-739. 